\title{
Thinking and Acting; Towards a Gendered Scholarship
}

\author{
Hilary Yerbury
}

\begin{abstract}
Scholarship is inextricably linked to education and development, yet often, when most needed, it is a resource difficult to come by and often the voices of women scholars are underrepresented. This chapter reflects on resources available to support scholarship and how a gendered approach to these resources can foster the development of informed policymakers and female scholars and through this, the growth and development of scholarship itself.
\end{abstract}

\section{Introduction}

Imagine creating a master's program in a new field of study, with the intention of developing a curiosity-driven culture which will lead to policy innovation and to scholarly research. On the checklist would be the questions about resources and about the capabilities of the students, taking into account the approaches to learning determined by the epistemological approach and by the field of study. Academics in a western university tradition will be familiar with this process, and will recognise that their university will probably have procedures in place to remedy gaps and weaknesses identified in providing the

How to cite this book chapter:

Yerbury, H. 2021. Thinking and Acting; Towards a Gendered Scholarship. In: Randell, S., Yerbury, H. and Escrig-Pinol, A. (eds.) Gender and Learning in Rwanda. Pp. 43-51. Sydney: UTS ePRESS. DOI: https://doi.org/10.5130/aag.d. License: CC BY-NC-ND. 
adequate resources and in developing the capabilities required of students for successful engagement in the program.

Now imagine starting this program without being able to complete this checklist, without being able to attest to the strength of the library's collection in the field and without being able to respond on the capabilities of prospective students; but prompted by a belief in the importance of curiosity-driven social change and the capacity of students who are passionate about social change to overcome many obstacles.

Such were some of the challenges facing staff and students when the master's program in Gender, Culture and Development began at what was then the Kigali Institute of Education (KIE) in Rwanda in early 2011. This chapter frames those challenges alongside a number of other challenges, as a series of realities to be confronted. Some of these will exist in the development of many programs of postgraduate education aimed at policy development and social change, whereas others will be particular to the context of this program of study. Among these challenges are the return to study of mature aged students including the balancing of work life, social life and study for the students; learning in a language which had not been the language of earlier education; the use of digital resources; the development of a scholarly to professional practice in an environment unfamiliar with such an approach; and the use of a feminist methodology in conceptualising the program of study.

\section{The Significance of Language}

Rwanda had been a Belgian colony and after independence in 1962, French had continued to be the official language, alongside Kinyarwanda, the local language. In 2008, prompted by the return after the genocide of many educated Tutsis and moderate Hutus from Uganda as well as by political considerations, the government introduced English as the medium of education in schools and in 2011 - the year in which the Master's in Gender, Culture and Development was to begin-KIE adopted English as its medium of instruction and deliberation. English became another official language, and many people in public administration managed to communicate in spoken English. However, in spite of reasonable facility with spoken English, written English was a challenge for some; in this way, the language of previous education and some associated cultural aspects had a significant effect on the students enrolled in the master's program, providing a clear reminder of the past for each student. A seemingly trivial example provides evidence of the distinction between those educated in French and those educated in English. Each student was to be provided with a notebook to document their career goals, an associated learning contract and their progress in completing the learning contract, as a kind of portfolio. The only shop selling notebooks of the kind anticipated did not have in stock enough notebooks with lined pages for each student to have 
one; to make up the number it would be necessary to buy some books with squared pages. When the books were distributed, the books with squared pages were readily taken up by the students whose previous education had been in French, as they had learned to write using the grid system of these pages and were more comfortable using them than using the books with plain lines.

More seriously, as Pennycook has noted (2001, p. 120), is that language use is linked to agency and thus to power. A challenge in class discussion was to support those not used to speaking in English so that their voices were not muted, and in assignment tasks to recognise that lack of facility with written English was likely to hamper the exploration of ideas and the presentation of thought and argument. The study groups established in the first weeks of the program, including Anglophone and Francophone students, and the coincidental ability of one of the teaching staff to speak French, and thus to act as a cultural and academic interpreter, helped to create a context where students were more able to demonstrate their agency equitably, at least during the period when they were settling in to their roles as learner and future scholar.

Language use and power are also linked to the topic of communication. The content of the master's program was designed to be challenging and the same time to normalise the discussion of topics fundamental to gender equity and social change. The students appeared to take on this challenge with gusto. Early in their program, they had to carry out a small scale research project, including collecting and analysing data and report on it to an audience of their peers: the academic staff of the program and the small number of senior scholars who accepted an invitation to attend. One group presented an investigation into the work and aspirations of women bus conductors - a bus company operating from the nearby bus station had recently employed two women conductors. The aspiration of one of these women to become a bus driver provoked an outburst from one of the invited members of the audience, for whom the thought of women driving was anathema, as 'everyone knew that there were times of the month when a woman was not rational and would be a danger to all. Here was clearly a topic where there was much to be done in the society to normalise discussion of such issues and work towards the social change which would accept the women as competent to work in many new jobs.

\section{Not Finding Their Voice}

Rwanda is a country which has prioritised access to internet-based services, completing a fibre-optic cabling project in 2011. Ownership of mobile telephones is high, with many people having phones linked to at least two out of the three networks. When the master's degree program commenced, KIE had effective internet access and the city of Kigali itself had a number of internet hotspots, although at the time access to the internet was relatively costly. Personal computers were not commonly owned. KIE, however, had 
relatively stable access to the internet and all of the buildings had Wi-Fi. This included the classrooms and the library. Access to a library was not a part of everyday life for most Rwandans. Most schools had no library and they would certainly not have had librarians. The Kigali Public Library was about to open when the program began. Thus, most students were unfamiliar with the range of services that an academic library could be expected to provide to support postgraduate education and research. The library at KIE (as noted elsewhere in these chapters) had a small collection to support the program, mainly consisting of donations from retiring scholars from overseas. However, it did have access to a significant number of electronic databases, a number of which provided access to the full text of journal articles and reports. Sessions with the chief librarian were invaluable in giving students skills in the searching of these online bibliographic databases. Other sessions helped the students gain skills in skimming and scanning journal articles and making notes from their reading.

The approach to education from the past, which for many had been an examination-based system, relying on the ability to remember and reproduce lectures and notes provided by the academic, encouraged many students to take their readings verbatim and include them in their classwork and their assessment tasks. From this, the lack of a broader understanding of information literacy was clear. Information literacy goes well beyond the finding and evaluation of relevant sources, to encompass the ethical practices of scholarship and research, including practices of references and citation. A significant challenge in overcoming what an Australian university would consider plagiarism arose, not because students deliberately sought to pass someone else's words off as their own, nor because they did not grasp the conventions of referencing, but because they were concerned that their use of English was not polished enough for the ideas they wanted to express. The importance for each student to develop his or her own voice, in order to express agency, was a new concept.

\section{Not Finding Other African Voices}

A significant issue which affects much scholarship across the continent of Africa is that there are comparatively few articles and books written by African scholars. In 2007, Ondari-Okemwa published a study that demonstrated the paucity of African voices in the scholarly literature. In 2006, more than 100,000 articles were published by scholars in the United States, a number which bore no relationship to the output of countries in sub-Saharan Africa; in Rwanda in 2005, according the UNESCO Science Report (2015), the number of scholarly articles published was 13, a figure which had risen to 143 in 2014. There are many reasons for this low level of publishing. A key factor is that knowledge production through scholarly processes is a cumulative process; each scholarly article builds on existing scholarship. The legacy of problems with access to scholarly resources in libraries will affect scholarship for some time to come 
(Lor \& Britz, 2005). A second issue is that local knowledge about Africa is overwhelmed by Western knowledge about Africa (Jackson et al., 2008). These systemic issues with scholarly publications should not be taken as evidence that African scholars do not write up the work that they do. It is the case that many African scholars produce reports and technical papers that have significant local impact, but which do not become part of the formal publishing record and are thus much more difficult for those not involved in the local community to access (Abrahams et al., 2008). It is also the case that there may be discrimination by the editors of some journals against African scholars. The editor of the Lancet, a major British medical journal, is reported to have said that if he chose to publish African authors, this might reduce the citation impact of his journal', leading to a situation that he described as 'a racist culture in journal decision-making' (Gray, 2010, p.10).

A fourth issue relates to the gendered nature of publishing. It is well documented that women scholars are seen to be less productive than their male counterparts. There is also anecdotal evidence indicating that women scholars may be more interested in achieving change in policy or in professional or social processes, so that they do not publish in the journals read by other scholars, but focus on professional journals and magazines, read by policymakers and practitioners. The consequence is that the particular concerns of women scholars may be less well represented in the literature and that their research approaches potentially are seen as having less validity.

\section{Windows and Mirrors}

This lack of representation in the literature indicates a marginalisation of the research interests, especially for women scholars. This is particularly significant in a context intending to raise awareness of issues of genderbased discrimination and to prepare people to be researchers attuned to the complexities of these issues in a country such as Rwanda. Galda (1998) writes of the windows and mirrors through which identity is constructed. This metaphor indicates the power of scholarly literature in providing insight into the worlds of others, and even into our own worlds, through the perception of others-these are the windows that give perspectives onto realities and also on to possibilities of other ways of acting. The metaphor of the mirror is perhaps more powerful as it functions at two levels. First it enables scholars and researchers to have the potential of seeing themselves reflected in the work of others, at least at an inspirational level. Secondly, it enables scholars and researchers to recognise in the work of others, something of their own situation. This is not the 'generalisability' of positivist research, where someone else's findings are relevant to one's own situation. Rather, this is a deeper recognition of something shared, the acknowledgement of a kind of imagined community, giving strength to the individual scholar who can glimpse that there are others 
working from a similar position. This metaphor of the importance of windows and mirrors is inherent in feminist scholarship.

Feminist scholarship itself presents a number of challenges to students and to researchers. It is, fundamentally, political, seeking a profound institutional change in society, from changes in the everyday use of language that has privileged the male over the female, to changes in attitudes and everyday practices, to changes to law and policy. Recognition of social problems is a starting point, but it is important for feminist scholars to recognise that in these social problems are broader, conceptual problems, problems in sociology, its concepts and theories. In other words, feminist scholarship must always seek to go beyond exposing inequalities in society. Early work in the western literature often focussed on economic inequalities, focussing on limitations in work opportunities, but this approach can constrain the understanding of the systems, structures and beliefs that prevent women from achieving economic equality. Several students expressed a concern with practices that they saw as gender-based violence, where men controlled economic resources in the family to the detriment of women. They noted that this was not necessarily an issue arising from the woman's lack of participation in the paid workforce, or even an issue arising from poverty as significant anecdotal evidence related to women who might be considered members of a social elite. It had been a tradition, and recent changes to legislation were difficult to implement when neither men nor women had learned any other way of managing the economic resources of the family. Societal beliefs and lack of practical experience were perceived as barriers to implementing solutions to this problem. Standpoint theory has been useful in positioning the importance of the point of view of women in the exploration of issues and problems - it highlights the inequalities that women suffer by presenting the analysis of a situation from the perspective of women. Yet, in a society seeking a fundamental shift in gender relations, there is the risk that feminist scholarship based on standpoint theory may marginalise the men who are working in support of societal change, by muting their voices.

In a context where the literature which might have provided windows and mirrors for the students enrolled in the first intake of the master's program was scarce and difficult to access, an obvious response was to create those windows and mirrors. Teaching staff selected readings that would go some way towards creating those windows that might provide perspectives in other realities and on ways of confronting these realities, especially through policy approaches and through approaches arising from community-based actions. Importantly, the learning activities themselves went some way towards creating the mirrors through which students as beginning scholars could recognise themselves and the issues of concern to them. Locally based investigations began a process of going beyond a recital of the facts of a situation, interpreting the findings in the light of the theoretical and conceptual underpinnings of the topics; students not only worked in groups to carry out these small-scale investigations, they 
were required to present them to their fellow students and sometimes to wider audiences. Even in this modest way, they began the scholarly process of creating new, conceptually based understandings of everyday realities, and considering the possibilities of this leading to institutional change.

Gender Studies centres elsewhere in Africa have identified similar problems with a lack of locally grounded material as a focus for discussion (Focus, 2009). Setting up some kind of publishing program was a common solution to the problem. More solidly established centres have been able to establish scholarly journals; as an example, the African Gender Institute in the University of Cape Town, was able to support a peer reviewed journal, Feminist Africa, and a significant website. Other centres placed an emphasis on producing working papers. This was the approach taken at the Centre for Gender, Culture and Development at KIE, which used the Centre's Facebook page to make these papers available. The use of the Facebook technology removed the barriers to access created by paywalls, registration and subscription. Conferences, with at least summaries of the papers in lieu of a full proceedings made available online, was another avenue through which research materials local to Rwanda were made public.

Another problem in the production of locally grounded research materials was identified as the lack of local people trained to the level of doctoral studies. The introduction of the MSocSciGD was seen to be the first step in a long process of preparing people to undertake doctoral study. Several students in the first cohort expressed the desire to become researchers, but the obstacles they have encountered mean that doctoral education remains a dream for most.

\section{New Ways of Thinking and Acting}

In spite of the problems with language, with the gaps in resources, the lack of African voices and locally grounded research materials supporting the development of the students in this program, nonetheless, it is clear that much has been achieved. Small beginnings, emerging from ways of conceptualising situations as well as living them, have led to powerful changes. It should be said that most of the students in the first cohort of the master's degree program had the capacity for implementing societal change because of their employment, in government departments and in NGOs. The program of education, based on feminist scholarship, brought new ways of thinking and in turn facilitated the development of new approaches to solutions as they became informed policymakers. The real challenge in institutional change is rarely the passing of new laws. Instead, it is in the implementation of the policies needed to support the new legislation and in the awareness raising, education and practical assistance which helps people to adjust and change their behaviour. The gendered approach to the learning in the course was no doubt an important influence in both personal development and institutional change in the policy 
context. It also seems, in a simple and unpretentious way, to have begun the development of scholars informed by a gendered approach and this will eventually lead to the growth and development of scholarship itself.

\section{References}

Abrahams, L et al. 2008, Opening Access to Knowledge in Southern African Universities, Southern African Universities Regional Association.

Focus on Gender Centres in Africa: Proceedings of an International Conference, 7-8 December 2009, Le Printemps Hotel, Kigali, Rwanda.

Galda, L 1998, 'Mirrors and windows: Reading as transformation', in Raphael, $\mathrm{T}$ and $\mathrm{Au}, \mathrm{K}$ (eds) Literature-based Instruction: Reshaping the Curriculum, Christopher-Gordon Publishers, Norwood, MA, pp. 1-12.

Gray, E 2009/2010, 'Access to Africa's knowledge: publishing development research and measuring value', The African Journal of Information Communication, no.10. Available at: https://journals.co.za/content/ journal/10520/EJC-18cef220e5 [Accessed 03/31/20].

Jackson, S, Batcheler, A, Edwards, P, Bowker, G, Cisler, S \& Starr, S 2008, Extending African Knowledge Infrastructures: Sharing, Creating, Maintaining. A Report for the World Bank Knowledge for Development Program March 2008. Available at: https://deepblue.lib.umich.edu/ bitstream/handle/2027.42/61201/Jackson\%20et\%20al,\%20Extending\%20 African\%20Knowledge\%20Infrastructures\%20(March\%202008).pdf;jsessi onid=CE00AD9BC17C08D9CFE7826D73076748? sequence $=1$ [Accessed 03/31/20].

Lor, P and Britz, J 2005, 'Knowledge production from an African perspective: International information flows and intellectual property', International Information and Library Review, volume 37, number 2, pp. 61-76. http:// dx.doi.org/10.1016/j.iilr.2005.04.003 [Accessed 03/31/20].

Ondari-Okemwa, E 2007, 'Scholarly publishing in sub-Saharan Africa in the twenty-first century: Challenges and opportunities', First Monday, vol. 12, no. 10, https://firstmonday.org/ojs/index.php/fm/article/view/1966/1842 [Accessed 03/31/20].

Pennycook, A 2001, Critical applied linguistics: a critical introduction, Erlbaum Associates, Mahwah, USA.

UNESCO Science Report: Towards 2030, 2015, https://en.unesco.org/unesco_ science_report [Accessed 03/31/20]. 


\section{Contributor Biography}

Hilary Yerbury has worked on programs to support the development of researchers, both as students and as established academics. Appointed Adjunct Professor and formerly Associate Professor in Information Management at the University of Technology Sydney, she brings a diverse background in European social and political cultures, anthropology, librarianship and development studies to the important topic of the use of information in everyday decisionmaking and in social change. She is a passionate supporter of open access scholarly publishing and a mentor to young scholars. She has extensive experience in working with young people on development issues. 